\title{
US chiropractors' attitudes, skills and use of evidence-based practice: A cross-sectional national survey
}

Michael J Schneider ${ }^{* *}$, Roni Evans ${ }^{2}$, Mitchell Haas ${ }^{3}$, Matthew Leach ${ }^{4}$, Cheryl Hawk ${ }^{5}$, Cynthia Long ${ }^{6}$, Gregory D Cramer ${ }^{7}$, Oakland Walters ${ }^{8}$, Corrie Vihstadt ${ }^{2}$ and Lauren Terhorst $^{9}$

\begin{abstract}
Background: Evidence based practice (EBP) is being increasingly utilized by health care professionals as a means of improving the quality of health care. The introduction of EBP principles into the chiropractic profession is a relatively recent phenomenon. There is currently a lack of information about the EBP literacy level of US chiropractors and the barriers/facilitators to the use of EBP in the chiropractic profession.

Methods: A nationwide EBP survey of US chiropractors was administered online (Nov 2012-Mar 2013) utilizing a validated self-report instrument (EBASE) in which three sub-scores are reported: attitudes, skills and use. Means, medians, and frequency distributions for each of the sub-scores were generated. Descriptive statistics were used to analyze the demographic characteristics of the sample. Means and proportions were calculated for all of the responses to each of the questions in the survey.

Results: A total of 1,314 US chiropractors completed the EBASE survey; the sample appeared to be representative of the US chiropractic profession. Respondents were predominantly white (94.3\%), male (75\%), 47 (+/- 11.6) years of age, and in practice for more than 10 years (60\%). EBASE sub-score means (possible ranges) were: attitudes, 31.4 (8-40); skills, 44.3 (13-65); and use, 10.3 (0-24). Survey participants generally held favorable attitudes toward EBP, but reported less use of EBP. A minority of participants indicated that EBP coursework (17\%) and critical thinking (29\%) were a major part of their chiropractic education. The most commonly reported barrier to the use of EBP was "lack of time". Almost 90\% of the sample indicated that they were interested in improving their EBP skills.

Conclusion: American chiropractors appear similar to chiropractors in other countries, and other health professionals regarding their favorable attitudes towards EBP, while expressing barriers related to EBP skills such as research relevance and lack of time. This suggests that the design of future EBP educational interventions should capitalize on the growing body of EBP implementation research developing in other health disciplines. This will likely include broadening the approach beyond a sole focus on EBP education, and taking a multilevel approach that also targets professional, organizational and health policy domains.
\end{abstract}

Keywords: Evidence-based medicine, Chiropractic, Complementary and alternative medicine, Survey research, Dissemination and implementation, Knowledge translation

\footnotetext{
*Correspondence: mjs5@pitt.edu

'Department of Physical Therapy, School of Health and Rehabilitation

Sciences, Clinical and Translational Science Institute, University of Pittsburgh,

Pittsburgh, PA, USA

Full list of author information is available at the end of the article
} 


\section{Background}

Evidence-based practice (EBP) has been steadily advocated since the mid 1990's [1,2] and has increasingly been adopted as a foundational framework for improving the quality of healthcare delivery systems $[3,4]$. Despite the growing awareness of EBP, there still remains a large gap between this appreciation of EBP and the actual uptake and application of EBP in clinical settings. This gap between knowledge and awareness of EBP - and actual clinical use of EBP - is found in almost all healthcare fields, including medicine, nursing, and physical therapy $[5,6]$.

Over the past decade the chiropractic profession has also embraced EBP, as evidenced by new EBP educational programs at chiropractic institutions [7-11] and the creation of professional evidence-based chiropractic guidelines [12-16]. However, while the enthusiasm for EBP in chiropractic is encouraging, a key aspect of its success will be whether or not it translates to changes in clinical practice. These changes would include the reduced use of unsupported clinical tests and procedures, as well as increased emphasis on those with an evidence base [17].

Dissemination and implementation research provides the means to bridge the gap between EBP principles and their application in clinical practice. This is accomplished by examining the mechanisms by which research evidence is spread and affects change in healthcare providers' attitudes and beliefs, and by evaluating strategies for changing healthcare professionals' behaviors to include the uptake of evidence-based clinical practices [18].

Chiropractic is one of the largest complementary and alternative medicine (CAM) professions in the United States. An important step for addressing the EBP gap in the chiropractic profession is to first understand chiropractors' attitudes and knowledge related to EBP, as well as the perceived barriers and facilitators to its application. Much of what is currently known is based on studies performed outside the United States. Walker et al. reported the results of an EBP survey showing that most of the 584 Australian chiropractors surveyed held positive attitudes towards EBP, thought EBP was useful, and were interested in improving their EBP skills [19]. However, despite their favorable inclination toward EBP, many Australian chiropractors stated they did not routinely use clinical practice guidelines. The three main barriers to the uptake of EBP identified in this study were: insufficient time, lack of generalizability of evidence to patient population, and inability to apply research findings to individual patients [19]. Similarly, researchers from Canada [20] and Great Britain [21] have found that accessibility to research, knowledge of how to access research, and critical appraisal skills are poor amongst chiropractors.

A study in a sub-specialty of 144 chiropractic orthopedists in the US also found favorable attitudes towards
EBP, and a desire for EBP post-graduate continuing education [22]. The most frequently reported barriers to EBP in this study were lack of relevant clinical evidence and lack of time. Facilitators to EBP included internet and database access, online EBP educational materials, critical reviews of chiropractic research, and ability to download full-text articles. The findings of this study are limited however by its small and specialized sample; consequently, the factors associated with the uptake of EBP by the US chiropractic profession still remain poorly understood.

The purpose of this article is to describe the results of a cross-sectional survey of US chiropractors' attitudes, skills and use of research evidence in clinical practice, as well as the barriers and facilitators to use of EBP.

\section{Methods}

\section{Study design and setting}

This was a cross-sectional survey conducted online between November 17, 2012 and March 5, 2013. The survey was administered electronically through the University of Pittsburgh (UPitt), Pittsburgh, Pennsylvania, using the UPitt web platform.

\section{Ethics}

Ethical approval (PRO12060417) was obtained through the University of Pittsburgh's (UPitt) institutional review board (IRB), which granted "exempt status" in June 2012. Informed consent was secured from all subjects on the homepage of the research website, prior to participation in the survey.

\section{Context}

The Distance Education Online Intervention for EvidenceBased Practice Literacy (DELIVER) project is a two-phase NIH/NCCAM-funded study (R21 AT007547) designed to evaluate the effectiveness of an online EBP educational program on chiropractors' attitudes, skill, and use of EBP. This cross-sectional survey comprised the first phase of the DELIVER study and served as a baseline measure of EBP literacy against which to analyze the effectiveness of an online EBP educational program (second phase).

\section{Participants \& recruitment}

The survey was open to all Doctors of Chiropractic (DCs) in the US who had internet access and a valid email address. A convenience sample of DCs were recruited primarily by emails forwarded to the membership rosters of several cooperating organizations including the following: American Chiropractic Association, Council on Chiropractic Guidelines and Practice Parameters, Congress of Chiropractic State Associations, Sacro Occipital Research Society International, Activator Methods, US ChiroDirectory, International College of Applied Kinesiology, the Pediatric 
Councils of the American Chiropractic Association and International Chiropractors Association.

These organizations provided email-forwarding services through their respective membership lists, which created a potential pool of over 30,000 DCs. The forwarded email message described a unique opportunity to participate in an online survey; participation was incentivized by offering participants the opportunity to enter a drawing to win an Apple iPad ${ }^{\mathrm{m} \text {. }}$. Recipients of the email were encouraged to forward the message on to their colleagues. Articles announcing the study and inviting readers to participate were published in two national chiropractic publications; Dynamic Chiropractic [23] and the Journal of American Chiropractic Association [24]. Another national chiropractic publication - The American Chiropractor - announced the study by sending an email blast to its national circulation of DCs.

\section{Questionnaire and outcomes}

The Evidence-Based Practice Attitude and Utilization SurvEy (EBASE) is a self-administered instrument designed to measure CAM providers' attitudes, skills and use of EBP [25]. The instrument has demonstrated good internal consistency, content validity, and acceptable test-retest reliability [26]. Minor modifications of a few EBASE items were required to ensure the language was appropriate for use with chiropractors [22]. These changes were made in consultation with the survey developer (ML) to ensure the structure and intent of the modified questions were not altered in any manner that would jeopardize the validity of the original survey. Only the demographics section (Part G) required major modifications to be relevant to the chiropractic profession.

Our modified version of the EBASE contains 75 items and is divided into 7 parts (Parts A-G); Parts A-F each address a different EBP construct, and Part G contains demographic items only. Each question within these parts allowed the participant 5 possible responses, which were rated numerically from 1 to 5 for Parts A and B, and from 0 to 4 for Part D. Although there are 7 parts to this survey, only 3 parts generate sub-scores: Parts A (Attitudes), B (Skill), and D (Use). The 4 remaining parts of the EBASE are not scored, including Part $C$ (Training \& Education), Part E (Barriers), Part F (Facilitators) and Part G (Demographics). The completion time of the online EBASE is approximately 10-12 minutes (see Additional file 1 for a copy of the modified EBASE survey and the scoring rubric used for calculating the three sub-scores).

\section{Survey administration and data collection}

Interested DCs were invited to follow a link to a dedicated UPitt website where they could obtain detailed information about the study procedures and register for the study by submitting an email address. Participants were subsequently emailed a password to enter the survey site, an effort aimed at preventing multiple responses from the same individual. To encourage honest and transparent responses, anonymity was insured by assigning a unique identification number to each registered DC, which was used to identify the respondent's survey data. As participants completed the survey, responses were captured through a secure data capturing feature/ system, Web Data Xpress, an interface that allows for direct entry and storage of data within a designated SQL Server database. This method of data capture is resource-efficient and minimizes human error by avoiding the need for manual data entry.

\section{Data analysis}

Data were analyzed using SPSS version 22 (SPSS Inc., Chicago, IL, USA). Since this was a cross-sectional survey we calculated descriptive statistics including response frequencies and means for each item in Parts A, $\mathrm{B}, \mathrm{D}, \mathrm{E}$ and $\mathrm{F}$ and response frequencies for Parts $\mathrm{C}$ and G. The attitudes, skills, and use sub-scores were calculated using the scoring rubric (see Additional file 1) developed with the original EBASE. This involves summing the first eight items of Parts A (response range $1-5$; total score range of $8-40$ ), all 13 of the items of Part B (response range 1-5; total score range of 13-65), and the first 6 items of Part D (response range 0-4; total score range of $0-24)$. Frequency distributions for the group sub-score means for Part A, B and D were also calculated. Higher sub-scores indicate higher selfreported levels of attitudes (Part A), skills (Part B) and use (Part D) of EBP.

\section{Results}

Sample Size

A total of 1,314 US chiropractors responded to the survey.

\section{Participant characteristics (Demographics and Education/ Training)}

Table 1 provides a summary of the frequencies of the demographic characteristics of the participants. The majority of the sample were male (75\%), Caucasian (94\%), practiced as sole proprietors $(72 \%)$ and held a Bachelor's or higher level graduate degree in addition to their chiropractic degree (>80\%). The average age of our sample was 47 years (range: 24 to 85 years), and the mean number of years in practice was 17 years (range: 0 to 30 years or more).

Only a small minority of the sample indicated that the following topics were major parts of their chiropractic education: coursework about EBP (17\%), applying research evidence to clinical practice (13\%), and critical thinking/analysis (29\%) (Table 2). Eleven percent of the 
Table 1 Demographic characteristics of the 1,314 American chiropractors who completed the online evidence-based practice survey

\begin{tabular}{|c|c|c|}
\hline Variable & Characteristic & n (\%) \\
\hline \multirow[t]{2}{*}{ Gender } & Male & $989(75.3)$ \\
\hline & Female & $325(24.7)$ \\
\hline Age & $\begin{array}{l}\text { Mean }=46.7 \text { yrs }(S D=11.6) \\
\text { Range }=24-85 \text { yrs }\end{array}$ & \\
\hline \multirow[t]{4}{*}{ Race } & White & $1239(94.3)$ \\
\hline & Black & $13(1.0)$ \\
\hline & Asian & $33(2.5)$ \\
\hline & Mixed Race/Other & $29(2.2)$ \\
\hline \multirow{7}{*}{$\begin{array}{l}\text { Years since chiropractic } \\
\text { graduation }\end{array}$} & $0-5$ & $273(20.8)$ \\
\hline & $6-10$ & $146(11.1)$ \\
\hline & $11-15$ & $187(14.2)$ \\
\hline & $16-20$ & $159(12.1)$ \\
\hline & $21-25$ & $170(12.9)$ \\
\hline & $26-29$ & $144(11.0)$ \\
\hline & $\begin{array}{l}30 \text { or more Mean }=17 \mathrm{yrs} \text {; } \\
\text { Range }=0-30 \text { or more yrs }\end{array}$ & $235(17.9)$ \\
\hline \multirow[t]{5}{*}{ Highest education level } & High School & $17(1.3)$ \\
\hline & Associate's Degree & $214(16.3)$ \\
\hline & Bachelor's Degree & $821(62.5)$ \\
\hline & Master's Degree & $226(17.2)$ \\
\hline & Doctorate & $36(2.7)$ \\
\hline \multirow[t]{6}{*}{ Region of practice } & Midwest & $380(28.9)$ \\
\hline & Northeast & $287(21.8)$ \\
\hline & West & $264(20.1)$ \\
\hline & Southeast & $245(18.6)$ \\
\hline & Southwest & $131(10.0)$ \\
\hline & Non-continental US & $7(0.5)$ \\
\hline \multirow[t]{3}{*}{ Geographic setting } & Suburban & $629(47.9)$ \\
\hline & City & $449(34.2)$ \\
\hline & Rural & $236(18.0)$ \\
\hline \multirow[t]{6}{*}{ Patients seen daily } & $0-10$ & $367(27.9)$ \\
\hline & $11-20$ & $455(34.6)$ \\
\hline & $21-30$ & $259(19.7)$ \\
\hline & $31-40$ & $126(9.6)$ \\
\hline & $41-50$ & $60(4.6)$ \\
\hline & $\begin{array}{l}51 \text { or more Median }=20 / \text { day; } \\
(\mathrm{IQR}=10-30) \text { Range }=0-100 / \text { day }\end{array}$ & $47(3.6)$ \\
\hline
\end{tabular}

Focus of clinical practice Musculoskeletal focus

$869(66.1)$

Spine and extremities $\quad 742(56.5)$

Spine $\quad 72(5.5)$

Sports $\quad 55(4.2)$

Non-musculoskeletal focus

Family care

Subluxation-based
Table 1 Demographic characteristics of the 1,314 American chiropractors who completed the online evidence-based practice survey (Continued)

\begin{tabular}{lll}
\hline & Wellness/Prevention & $105(8.0)$ \\
& Non-musculoskeletal & $20(1.5)$ \\
& Pediatrics & $14(1.1)$ \\
Clinical role & Sole Proprietor & $946(72.0)$ \\
& Partner or group practice & $171(13.0)$ \\
& Associate or employee & $144(11.0)$ \\
& Hospital-based practice & $53(4.0)$ \\
Organizational & Unaffiliated & $722(55.0)$ \\
membership & American Chiropractic & $526(40.0)$ \\
& Assoc. (ACA) & \\
& International Chiropractors & $66(5.0)$ \\
\hline SD = Standard Deviation. IQR $=$ Interquartile Range. Yrs = Years. &
\end{tabular}

sample indicated they never had any critical thinking/ analysis included in their chiropractic education. Almost half the sample reported that they had never received any education/training on conducting systematic reviews (48\%) or clinical research (42\%).

\section{Descriptive results for parts A, B and D (Attitudes, Skills and Use)}

Participants held a generally favorable attitude (Part A) toward EBP, with a mean attitude sub-score of 31.4 (range 8-40); while the frequency distribution was skewed to the left, the median sub-score (32.0) was close to the mean (Figure 1). The majority (>75\%) of participants gave responses of "agree" or "strongly agree" to most questions (Table 3). There were two individual attitude related items with which a smaller proportion of the respondents agreed: 1) "EBP takes into account a patient's preference for treatment" (42\% agree/strongly agree); and 2) "EBP takes into account my clinical experience when making clinical decisions" (65\% agree/strongly agree). It was also very interesting to note that the vast majority of our sample (89.5\%) agreed or strongly agreed with the statement "I am interested in learning or improving the skills necessary to incorporate EBP into my practice".

For self-reported skills in EBP (Part B) the mean subscore was 44.3 (range of 13-65) with a left skewed frequency distribution, and a median sub-score (44.0) similar to the mean (Figure 2). For the majority of skill items, more than half of respondents indicated a generally high level ('4' or '5') of self-reported skill in EBP (Table 4); however nearly a third of respondents rated their skills in the mid-range (' 3 ' on $1-5$ scale) for 11 of the 13 skill items. The two skills rated poorest were: 1) "conducting clinical research" (66\% of respondents) and 2) "conducting systematic reviews" (47\% of respondents). 
Table 2 Response frequency of Training/Education items (Part C of E-BASE)

\begin{tabular}{|c|c|c|c|c|c|c|c|c|c|}
\hline PART C Item & None & $\begin{array}{l}\text { Seminar } \\
(<1 \text { day })\end{array}$ & $\begin{array}{l}\text { Short course } \\
\text { (<1 week) }\end{array}$ & $\begin{array}{l}\text { Minor part of } \\
\text { chiropractic } \\
\text { education }\end{array}$ & $\begin{array}{l}\text { Major part of } \\
\text { chiropractic } \\
\text { education }\end{array}$ & $\begin{array}{l}\text { Minor part of } \\
\text { diplomate } \\
\text { education }\end{array}$ & $\begin{array}{l}\text { Major part of } \\
\text { diplomate } \\
\text { education }\end{array}$ & $\begin{array}{l}\text { Academic } \\
\text { diploma }\end{array}$ & $\begin{array}{l}\text { Informal } \\
\text { personal } \\
\text { study }\end{array}$ \\
\hline $\begin{array}{l}\text { Applying research evidence } \\
\text { to clinical practice }\end{array}$ & $8.1 \%$ & $23.4 \%$ & $5.7 \%$ & $23.4 \%$ & $13.1 \%$ & $3.7 \%$ & $3.9 \%$ & $1.8 \%$ & $17.0 \%$ \\
\hline $\begin{array}{l}\text { Critical thinking/critical } \\
\text { analysis }\end{array}$ & $10.8 \%$ & $8.4 \%$ & $5.3 \%$ & $21.7 \%$ & $29.0 \%$ & $2.7 \%$ & $3.8 \%$ & $3.4 \%$ & $14.9 \%$ \\
\hline $\begin{array}{l}\text { Evidence-based clinical } \\
\text { practice/evidence-based } \\
\text { chiropractic }\end{array}$ & $4.8 \%$ & $25.5 \%$ & $5.5 \%$ & $22.8 \%$ & $17.0 \%$ & $5.6 \%$ & $4.9 \%$ & $1.8 \%$ & $12.1 \%$ \\
\hline $\begin{array}{l}\text { Conducting systematic } \\
\text { reviews or meta-analysis }\end{array}$ & $47.6 \%$ & $6.3 \%$ & $6.5 \%$ & $21.8 \%$ & $3.7 \%$ & $1.9 \%$ & $0.6 \%$ & $1.2 \%$ & $10.4 \%$ \\
\hline Conducting clinical research & $42.2 \%$ & $6.3 \%$ & $6.1 \%$ & $26.5 \%$ & $4.0 \%$ & $2.4 \%$ & $0.9 \%$ & $1.8 \%$ & $9.8 \%$ \\
\hline
\end{tabular}

These are responses to the question "Please indicate the highest level of training/education you have received in the following areas".

The mean sub-score for use of EBP (Part D) was 10.3 (range of 0-24). The frequency distribution was skewed to the right, with a median sub-score of 8.0 (Figure 3). While 36\% reported not consulting magazines, laypersons or self-help books for clinical decision making in the previous month, $23 \%$ also reported not using research findings to change their clinical practice and 29\% did not use an online database to search for practicebased literature or research findings. About $45 \%$ of the sample indicated that only a small, very small, or no proportion of their practice was based on clinical research evidence (Table 5).

\section{Descriptive results for parts $E$ and $F$ (Barriers and Facilitators to EBP Uptake)}

When presented with a list of potential barriers to EBP uptake (Part E), most ( $>75 \%)$ participants indicated that the majority of the factors were either "not a barrier" or a "minor barrier" (Table 6), with a few notable exceptions. Items rated as being moderate or major barriers to EBP uptake included: 1) 'lack of time' (48\%); 2) 'lack of clinical evidence about CAM' (44\%); 3), 'lack of industry support' (37\%); and 4) 'lack of incentive' (36\%). Approximately a quarter of respondents cited insufficient skills for interpreting (27\%); locating (23\%) and critically appraising research (24\%); lack of colleague support for EBP (23\%); and lack of relevance to chiropractic practice (24\%).

In terms of the perceived usefulness of various factors in facilitating the uptake of EBP (Part F) in clinical practice, over $70 \%$ of respondents indicated all 10 items as either "moderately useful" or "very useful" (Table 7). The two items that received the greatest percentage of "very useful" responses were "access to the internet" (78\%) and "access to free online databases" (70\%). Items

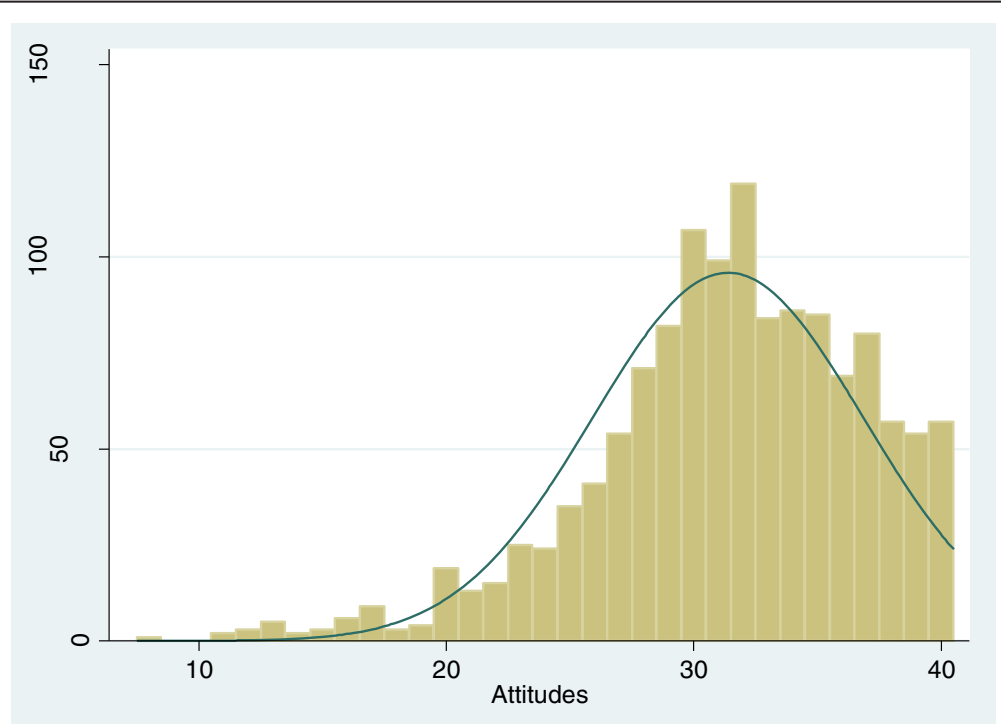

Figure 1 Frequency distribution of Attitudes sub-scores. The $Y$-axis indicates the number of survey participants and the $X$-axis indicates the Attitudes subscores. The mean sub-score was $31.4(\mathrm{sd}=5.5)$ with a possible range of 8 to 40 (8 items scored $1-5)$. Median = 32.0 (IQR=28-35). 
Table 3 Response frequency and means of Attitudes toward EBP items (Part A of E-BASE)

\begin{tabular}{|c|c|c|c|c|c|c|}
\hline Part A Items & $\begin{array}{l}\text { Strongly } \\
\text { Disagree(1) }\end{array}$ & Disagree(2) & Neutral(3) & Agree(4) & $\begin{array}{l}\text { Strongly } \\
\text { Agree(5) }\end{array}$ & $\begin{array}{l}\text { Mean } \\
\text { (Range=1-5) }\end{array}$ \\
\hline $\begin{array}{l}\text { *I am interested in learning or improving the skills } \\
\text { necessary to incorporate EBP into my practice }\end{array}$ & $0.9 \%$ & $2.1 \%$ & $7.5 \%$ & $42.8 \%$ & $46.7 \%$ & 4.3 \\
\hline $\begin{array}{l}\text { *Evidence based practice (EBP) is necessary in the } \\
\text { practice of chiropractic }\end{array}$ & $2.1 \%$ & $3.5 \%$ & $9.1 \%$ & $39.6 \%$ & $45.7 \%$ & 4.2 \\
\hline $\begin{array}{l}\text { *Professional literature (i.e. journals } \& \text { textbooks) and } \\
\text { research findings are useful in my day-to-day practice }\end{array}$ & $0.9 \%$ & $3.4 \%$ & $9.6 \%$ & $53.4 \%$ & $32.7 \%$ & 4.1 \\
\hline *EBP improves the quality of my patient's care & $2.1 \%$ & $4.4 \%$ & $14.4 \%$ & $43.2 \%$ & $35.9 \%$ & 4.1 \\
\hline *EBP assists me in making decisions about patient care & $1.2 \%$ & $3.7 \%$ & $10.6 \%$ & $48.6 \%$ & $35.9 \%$ & 4.1 \\
\hline $\begin{array}{l}\text { Prioritizing EBP within chiropractic practice is } \\
\text { fundamental to the advancement of the profession }\end{array}$ & $2.4 \%$ & $7.8 \%$ & $13.3 \%$ & $39.8 \%$ & $36.7 \%$ & 4.0 \\
\hline $\begin{array}{l}\text { *EBP takes into account my clinical experience when } \\
\text { making clinical decisions }\end{array}$ & $2.3 \%$ & $14.8 \%$ & $17.7 \%$ & $41.5 \%$ & $23.7 \%$ & 3.7 \\
\hline $\begin{array}{l}\text { *The adoption of EBP places an unreasonable demand } \\
\text { on my practice [Note: Item is reverse coded] }\end{array}$ & $14.4 \%[5]$ & $43.2[4]$ & $29.1 \%[3]$ & $10.6 \%[2]$ & $2.7 \%[1]$ & 3.6 \\
\hline *EBP takes into account a patient's preference for treatment & $5.3 \%$ & $24.1 \%$ & $28.5 \%$ & $27.1 \%$ & $15.0 \%$ & 3.2 \\
\hline $\begin{array}{l}\text { There is a lack of evidence from clinical trials to support } \\
\text { most of the treatments I use in my practice }\end{array}$ & $13.5 \%$ & $42.2 \%$ & $17.7 \%$ & $22.6 \%$ & $4.0 \%$ & 2.6 \\
\hline
\end{tabular}

*The sum of the 8 items with asterisks comprises the "Attitudes" sub-score, which ranges from 8-40. See Figure 1 for frequency distribution graph of attitudes sub-scores. These are responses to the question "On a scale ranging from strongly disagree to strongly agree, how would you rate your opinion on the following statements?"

most frequently reported as "not useful" or "slightly useful" included: 1) "access to online tools to assist you to conduct your own critical appraisals of multiple research papers" (30\%), and 2) "access to research rating tools that facilitate critical appraisal of single research papers" (26\%).

\section{Discussion}

This is one of the largest studies to examine chiropractors' perspectives relative to EBP, and to our knowledge, the first national survey to be conducted in the United States. One other EBP study was performed in the US, however the sample was limited to mid-western chiropractors with advanced training in orthopedics [22]. Despite the large absolute sample size of our survey $(\mathrm{n}=$ $1,314)$, it represents only a small relative cross-sectional sample of the American chiropractic profession $(\mathrm{n}=$ $60,000)$ [27-29]. However, the demographic characteristics of our sample (Table 1) are strikingly similar to those reported by three National Board of Chiropractic Examiners' Job Analysis Reports [27-29]. This provides support for the generalizability of our survey results and makes us more confident that we have obtained a representative sample of US chiropractors.

The results suggest that our respondents generally have positive attitudes about evidence-based practice and a high level of self-reported skills in EBP, but only a modest level of EBP uptake in their clinical practices. These results are relatively similar to those reported from a recent EBP survey of Australian chiropractors [19] and are consistent with the observation that passive diffusion of knowledge does not automatically translate into clinical implementation [6]. Further, it emphasizes the need for high quality EBP continuing education programs to meet the needs of the chiropractic profession.

Our participants reported generally positive attitudes toward EBP, with most agreeing that EBP is important for improving practice, patient care, and advancing the profession. Noteworthy was that nearly a third strongly agreed that there is a lack of evidence from clinical trials to support most of the treatments I use in my practice'. Similarly, only $42 \%$ agreed or strongly agreed that 'EBP takes into account a patient's preference for treatment'. These findings suggest that the basic principles of EBP may be misunderstood by DCs given the original definition of EBP clearly states that clinical expertise, patient values and best available research evidence are all integral components of evidence-based practice [1]. However, these opinions might also reflect what has become a growing recognition across healthcare fields; that clinical research needs to become more patientoriented, pragmatic and generalizable to "real life" clinical practice [30].

Our sample of DCs reported that their poorest EBP skills were in conducting clinical research and/or systematic reviews; given that this survey was of practicing DCs without academic or research affiliation, this is not surprising. Distinctions have been drawn between the expectation for practitioners to be 'consumers' who 'use' research rather than 'manufacturers' who 'produce' research [31]; future studies should take this into consideration by ensuring that data collection instruments reflect this thinking. 


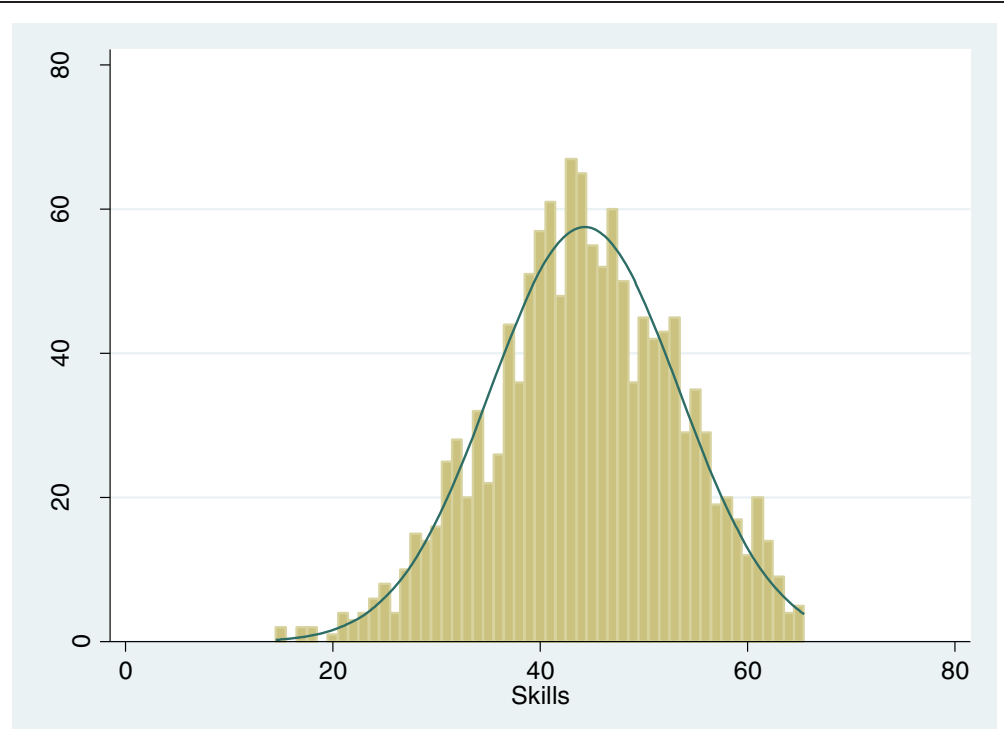

Figure 2 Frequency distribution of Skills sub-scores. The Y-axis indicates the number of survey participants and the X-axis indicates the Skills subscores. The mean sub-score was $44.3(\mathrm{sd}=9.1)$ with a possible range of 13 to $65(13$ items scored $1-5)$. Median $=44.0(\mathrm{IQR}=39-51)$.

Most of our sample reported above average skills in EBP, particularly in relation to identifying answerable clinical questions, identifying knowledge gaps in practice, locating professional literature and online database searching. However, nearly a third of respondents rated themselves only in the mid-range on nearly all of the EBP skill items. Some of these skills included the ability to synthesize research evidence, sharing evidence with colleagues, and using the findings from systematic reviews. Interestingly, while almost two-thirds reported above-average to advanced skills in using findings from clinical research, less than half reported the same level of skill in using findings from systematic reviews. This suggests that DCs have a limited understanding of the value and availability of systematic reviews, which is problem shared by many health professionals [32].

The introduction of EBP into the curricula of US chiropractic colleges is a relatively new phenomenon that has largely occurred over the past decade. The National Center for Complementary and Integrative Health (formerly NCCAM) has provided funding through its R25 mechanism to nine CAM colleges - four of them with chiropractic education programs - to develop institutional programs focused on teaching EBP. An

Table 4 Response frequency and means of Skills in EBP items (Part B of E-BASE)

\begin{tabular}{|c|c|c|c|c|c|c|}
\hline PART B Items & Poor (1) & $(2)$ & (3) & $(4)$ & Advanced(5) & Mean (Range $=1-5)$ \\
\hline Identifying answerable clinical questions & $0.3 \%$ & $3.0 \%$ & $18.6 \%$ & $52.5 \%$ & $25.6 \%$ & 4.0 \\
\hline Identifying knowledge gaps in practice & $0.4 \%$ & $3.5 \%$ & $29.5 \%$ & $50.0 \%$ & $16.7 \%$ & 3.8 \\
\hline Locating professional literature & $1.7 \%$ & $8.6 \%$ & $25.5 \%$ & $38.7 \%$ & $25.5 \%$ & 3.8 \\
\hline Online database searching & $3.7 \%$ & $12.1 \%$ & $25.3 \%$ & $35.2 \%$ & $23.7 \%$ & 3.6 \\
\hline Retrieving evidence & $3.0 \%$ & $11.4 \%$ & $28.5 \%$ & $38.5 \%$ & $18.6 \%$ & 3.6 \\
\hline Critical appraisal of evidence & $1.9 \%$ & $10.6 \%$ & $31.2 \%$ & $42.4 \%$ & $13.9 \%$ & 3.6 \\
\hline Synthesis of research evidence & $3.7 \%$ & $15.8 \%$ & $34.6 \%$ & $36.6 \%$ & $9.3 \%$ & 3.3 \\
\hline Applying research evidence to patient cases & $1.7 \%$ & $8.0 \%$ & $27.2 \%$ & $48.9 \%$ & $14.2 \%$ & 3.7 \\
\hline Using findings from clinical research & $1.5 \%$ & $7.1 \%$ & $29.1 \%$ & $47.4 \%$ & $14.9 \%$ & 3.7 \\
\hline Sharing evidence with colleagues & $4.8 \%$ & $18.0 \%$ & $30.6 \%$ & $33.3 \%$ & $13.3 \%$ & 3.3 \\
\hline Using findings from systematic reviews & $6.3 \%$ & $19.2 \%$ & $30.7 \%$ & $34.0 \%$ & $9.8 \%$ & 3.2 \\
\hline Conducting systematic reviews & $17.0 \%$ & $29.9 \%$ & $29.9 \%$ & $18.4 \%$ & $4.8 \%$ & 2.6 \\
\hline Conducting clinical research & $36.8 \%$ & $29.5 \%$ & $20.9 \%$ & $10.3 \%$ & $2.5 \%$ & 2.1 \\
\hline
\end{tabular}

The sum of all 13 items comprises the "skills" sub-score, which ranges from 13-65. See Figure 2 for frequency distribution graph of skills sub-scores. These are responses to the question "On a scale from 1 to 5 , with 1 being poor and 5 being advanced, how would you rate your skills in the following areas"? 


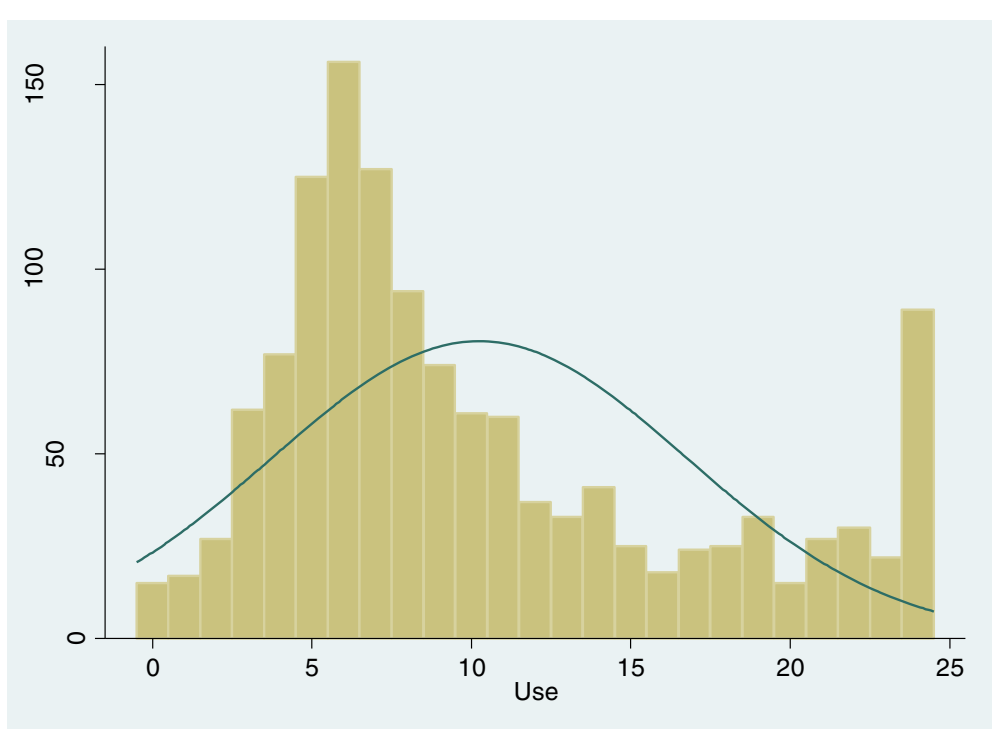

Figure 3 Frequency distribution of Use sub-scores. The Y-axis indicates the number of survey participants and the X-axis indicates the Use subscores. The mean sub-score was $10.3(\mathrm{sd}=6.5)$ with a possible range of 0 to $24(6$ items scored $0-4)$. Median value $=8.0(\mathrm{IQR}=6-14)$.

overarching goal of these R25 research education grants was to provide CAM faculty and students with the skills they need to apply a rigorous evidence-based perspective to their training and practice. Adding research literacy and EBP competencies to the curricula at these CAM colleges has led to changes in their institutional cultures, such as increased faculty use of EBP case studies in the classroom and student-led research/journal clubs [33-35]. However, with approximately two thirds of our sample receiving their chiropractic training 11 to 30 years ago, it is

Table 5 Response frequency and means of Use of EBP items (Part D of E-BASE)

\begin{tabular}{|c|c|c|c|c|c|c|c|}
\hline PART D Item & $\begin{array}{l}\text { None } \\
(0)\end{array}$ & $\begin{array}{l}\text { Very small } \\
(1-25 \%)(1)\end{array}$ & $\begin{array}{l}\text { Small } \\
(26-50 \%)(2)\end{array}$ & $\begin{array}{l}\text { Moderate } \\
(51-75 \%)(3)\end{array}$ & $\begin{array}{l}\text { Large } \\
(76-99 \%)(4)\end{array}$ & $\begin{array}{l}\text { All } \\
(100 \%)(5)\end{array}$ & $\begin{array}{l}\text { Mean } \\
\text { (Range=1-5) }\end{array}$ \\
\hline $\begin{array}{l}\text { What percentage of your practice do you } \\
\text { estimate is based on clinical research evidence } \\
\text { (i.e. evidence from clinical trials)? }\end{array}$ & $2.7 \%$ & $21.2 \%$ & $21.0 \%$ & $32.3 \%$ & $21.0 \%$ & $1.8 \%$ & 2.5 \\
\hline PART D Items & $\begin{array}{l}0 \text { times } \\
(0)\end{array}$ & $\begin{array}{l}1-5 \text { times } \\
\text { (1) }\end{array}$ & $\begin{array}{l}6-10 \text { times } \\
(2)\end{array}$ & $\begin{array}{l}11-15 \text { times } \\
\text { (3) }\end{array}$ & $\begin{array}{l}\text { 16+ times } \\
\text { (4) }\end{array}$ & & $\begin{array}{l}\text { Mean } \\
\text { (Range=0-4) }\end{array}$ \\
\hline $\begin{array}{l}\text { *I have read/reviewed professional literature } \\
\text { (i.e. professional journals \& textbooks) related } \\
\text { to my practice }\end{array}$ & $3.4 \%$ & $41.9 \%$ & $22.6 \%$ & $8.7 \%$ & $23.4 \%$ & & 2.1 \\
\hline $\begin{array}{l}\text { *I have used an online search engine to search } \\
\text { for practice related literature or research }\end{array}$ & $7.9 \%$ & $39.0 \%$ & $23.5 \%$ & $9.9 \%$ & $19.7 \%$ & & 1.9 \\
\hline $\begin{array}{l}\text { *I have read/reviewed clinical research findings } \\
\text { related to my practice }\end{array}$ & $7.8 \%$ & $48.3 \%$ & $17.4 \%$ & $7.5 \%$ & $19.0 \%$ & & 1.8 \\
\hline $\begin{array}{l}\text { *I have used professional literature or research } \\
\text { findings to assist my clinical decision making }\end{array}$ & $11.0 \%$ & $52.1 \%$ & $14.8 \%$ & $6.3 \%$ & $15.8 \%$ & & 1.6 \\
\hline $\begin{array}{l}\text { *I have used an online database to search } \\
\text { for practice related literature or research }\end{array}$ & $28.6 \%$ & $36.5 \%$ & $12.4 \%$ & $6.4 \%$ & $16.1 \%$ & & 1.4 \\
\hline $\begin{array}{l}\text { *I have used professional literature or research } \\
\text { findings to change my clinical Practice }\end{array}$ & $23.2 \%$ & $48.9 \%$ & $11.3 \%$ & $4.3 \%$ & $12.3 \%$ & & 1.3 \\
\hline $\begin{array}{l}\text { I have consulted a colleague or industry } \\
\text { expert to assist my clinical decision making }\end{array}$ & $22.5 \%$ & $51.8 \%$ & $13.5 \%$ & $4.7 \%$ & $7.5 \%$ & & 1.2 \\
\hline $\begin{array}{l}\text { I have referred to magazines, layperson/ } \\
\text { self-help books, or non-government/ } \\
\text { non-education institution websites to } \\
\text { assist my clinical decision making }\end{array}$ & $35.6 \%$ & $43.8 \%$ & $11.1 \%$ & $4.2 \%$ & $5.3 \%$ & & 1.0 \\
\hline
\end{tabular}

*The sum of the 6 items with asterisks comprises the "Use" sub-score, which ranges from 0-24. See Figure 3 for frequency distribution graph of the "use" sub-scores. These are responses to the question "Indicate how often you have performed the following activities over the last month". 
Table 6 Response frequency and means of Barriers to EBP uptake items (Part E of E-BASE)

\begin{tabular}{|c|c|c|c|c|c|}
\hline PART E Items & $\begin{array}{l}\text { Not a barrier } \\
\text { (1) }\end{array}$ & $\begin{array}{l}\text { Minor barrier } \\
(2)\end{array}$ & $\begin{array}{l}\text { Moderate barrier } \\
\text { (3) }\end{array}$ & $\begin{array}{l}\text { Major barrier } \\
\text { (4) }\end{array}$ & $\begin{array}{l}\text { Mean } \\
(\text { Range }=1-4)\end{array}$ \\
\hline Lack of time & $19.2 \%$ & $33.0 \%$ & $34.1 \%$ & $13.7 \%$ & 2.4 \\
\hline $\begin{array}{l}\text { Lack of clinical evidence in complementary } \\
\text { and alternative medicine }\end{array}$ & $18.9 \%$ & $37.2 \%$ & $32.2 \%$ & $11.7 \%$ & 2.4 \\
\hline Lack of industry support for EBP & $31.4 \%$ & $31.6 \%$ & $26.3 \%$ & $10.7 \%$ & 2.2 \\
\hline Lack of incentive to participate in EBP & $34.6 \%$ & $29.2 \%$ & $26.2 \%$ & $10.0 \%$ & 2.1 \\
\hline Insufficient skills for interpreting research & $34.3 \%$ & $38.7 \%$ & $19.9 \%$ & $7.1 \%$ & 2.0 \\
\hline Insufficient skills for locating research & $39.7 \%$ & $37.3 \%$ & $16.8 \%$ & $6.2 \%$ & 1.9 \\
\hline $\begin{array}{l}\text { Insufficient skills to critically appraise/evaluate } \\
\text { the literature }\end{array}$ & $35.8 \%$ & $39.8 \%$ & $18.8 \%$ & $5.6 \%$ & 1.9 \\
\hline Lack of colleague support for EBP & $44.1 \%$ & $32.7 \%$ & $17.0 \%$ & $6.2 \%$ & 1.9 \\
\hline $\begin{array}{l}\text { Insufficient skills to apply research findings to } \\
\text { clinical practice }\end{array}$ & $39.9 \%$ & $41.5 \%$ & $15.8 \%$ & $2.8 \%$ & 1.8 \\
\hline Lack of relevance to chiropractic practice & $47.1 \%$ & $29.1 \%$ & $17.8 \%$ & $6.0 \%$ & 1.8 \\
\hline Patient preference for treatment & $41.5 \%$ & $38.0 \%$ & $16.8 \%$ & $3.7 \%$ & 1.8 \\
\hline Lack of interest in EBP & $52.5 \%$ & $30.5 \%$ & $12.6 \%$ & $4.4 \%$ & 1.7 \\
\hline $\begin{array}{l}\text { Lack of resources (i.e. access to a computer, } \\
\text { the internet or online databases) }\end{array}$ & $60.0 \%$ & $26.8 \%$ & $10.4 \%$ & $2.8 \%$ & 1.6 \\
\hline
\end{tabular}

These are responses to the question "On a scale ranging from 'not a barrier' to 'major barrier', to what extent do the following factors prevent you from participating in $\mathrm{EBP}^{\prime \prime}$ ?

likely that many of our participants never received what would now be considered foundational training in EBP.

Additionally, our results suggest that educational emphasis should be focused on improving the skills of appraising and applying research evidence in clinical practice. This needs to be done in a way that provides clinicians with 'real life' clinical examples, in order to overcome the barriers of lack of interest or clinical relevance to chiropractic practice. This issue was addressed in the second phase of our project, which explores the effectiveness of online EBP educational modules and "booster exercises" that incorporate clinical examples

Table 7 Response frequency and means of Facilitators of EBP uptake items (Part F of E-BASE)

\begin{tabular}{|c|c|c|c|c|c|}
\hline PART F Items & $\begin{array}{l}\text { Not useful } \\
\text { (1) }\end{array}$ & $\begin{array}{l}\text { Slightly useful } \\
\text { (2) }\end{array}$ & $\begin{array}{l}\text { Moderately useful } \\
\text { (3) }\end{array}$ & $\begin{array}{l}\text { Very useful } \\
\text { (4) }\end{array}$ & $\begin{array}{l}\text { Mean } \\
\text { (Range = 1-4) }\end{array}$ \\
\hline Access to the Internet in your workplace & $3.4 \%$ & $5.2 \%$ & $13.5 \%$ & $77.9 \%$ & 3.7 \\
\hline $\begin{array}{l}\text { Access to free online databases in the workplace, such as } \\
\text { Cochrane and PubMed }\end{array}$ & $2.0 \%$ & $8.9 \%$ & $18.9 \%$ & $70.2 \%$ & 3.6 \\
\hline Ability to download full-text / full-length journal articles & $2.1 \%$ & $11.5 \%$ & $20.9 \%$ & $65.5 \%$ & 3.5 \\
\hline $\begin{array}{l}\text { Access to online education materials related to evidence } \\
\text { based practice }\end{array}$ & $1.4 \%$ & $9.3 \%$ & $23.7 \%$ & $65.6 \%$ & 3.5 \\
\hline $\begin{array}{l}\text { Access to critical reviews of research evidence relevant } \\
\text { to your field (these are critical reviews of multiple } \\
\text { research papers addressing a single topic) }\end{array}$ & $1.8 \%$ & $11.3 \%$ & $31.4 \%$ & $55.5 \%$ & 3.4 \\
\hline $\begin{array}{l}\text { Free access to online databases that usually require } \\
\text { license fees, such as DynaMed and CINAHL }\end{array}$ & $6.9 \%$ & $15.1 \%$ & $19.7 \%$ & $58.3 \%$ & 3.3 \\
\hline $\begin{array}{l}\text { Access to critically appraised topics relevant to your field } \\
\text { (these are critical appraisals of single research papers) }\end{array}$ & $2.2 \%$ & $15.6 \%$ & $35.2 \%$ & $47.0 \%$ & 3.3 \\
\hline $\begin{array}{l}\text { Access to tools used to assist the critical appraisal/evaluation } \\
\text { of research evidence }\end{array}$ & $3.4 \%$ & $17.6 \%$ & $36.7 \%$ & $42.3 \%$ & 3.2 \\
\hline $\begin{array}{l}\text { Access to research rating tools that facilitate critical appraisal } \\
\text { of single research papers }\end{array}$ & $4.3 \%$ & $21.9 \%$ & $35.5 \%$ & $38.3 \%$ & 3.1 \\
\hline $\begin{array}{l}\text { Access to online tools that assist you to conduct your own } \\
\text { critical appraisals of multiple research papers related to a } \\
\text { single topic }\end{array}$ & $6.8 \%$ & $22.9 \%$ & $30.4 \%$ & $39.9 \%$ & 3.0 \\
\hline
\end{tabular}


relevant to chiropractors. Results of the second phase of this project will be reported in a future publication.

The results of this survey also indicate that there are serious gaps in the uptake of research evidence into chiropractic practice, with nearly half reporting only a very small proportion of what they do in their clinical practice is based on research evidence. DCs appear to have challenges with performing online searches of the literature and interpreting the results of systematic reviews. Although most DCs in our sample reported they had above average skills in locating literature online, they also indicated that they did not engage in the uptake of EBP on a frequent basis (> six times a month). This apparent contradiction may be associated with the issues of time and lack of evidence, as discussed in the next paragraph. However, almost $90 \%$ of our sample indicated that they were interested in learning or improving the skills necessary to incorporate EBP into their practices (Table 3). Educational interventions and strategies are more likely to be successful if they are informed by known barriers and facilitators [36-39].

On the whole, most DCs indicated there were few barriers to their uptake of EBP, which is consistent with their generally positive attitudes toward EBP. It is worth noting however, that almost half of DCs indicated that the two biggest barriers to EBP uptake were lack of time' and 'lack of clinical evidence in CAM'. A sizeable proportion (a quarter to one third) also cited: 'lack of industry support'; 'lack of incentive'; 'insufficient skills for interpreting research'; 'locating and critically appraising research'; 'lack of colleague support for EBP'; and 'lack of relevance to chiropractic practice'. Many of the barriers identified in this study are similar to those found for chiropractors in Australia [19], Canada [20] and Great Britain [21] as well as a sub-specialty of chiropractic orthopedists in the US [22]. Interestingly, many of the same barriers are encountered in the medical and nursing professions $[5,6]$, leading us to conclude that the challenges facing the chiropractic profession in implementing EBP are not unique.

Interestingly, very few DCs indicated that computer, internet, or database access were barriers to their uptake of EBP. Coupled with our sample's perceived usefulness of all of the listed facilitator items, these findings underscore the importance of providing clinicians with training in EBP skills, particularly through online resources. Our findings also suggest a need for greater support from professional organizations to facilitate collegial support of EBP, as well as better collaboration between scientists and practitioners in the design of clinically applicable research. Indeed, while educational strategies are an important part of narrowing the gap between science and practice for chiropractic and other health disciplines, they will likely be insufficient on their own to accomplish true change. Comprehensive and multi-faceted approaches that take into account all the relevant levels affecting EBP, including professional, managerial, organizational and health systems, will likely be needed to integrate research into practice [41].

There were several limitations to this study. The first is inherent to any type of survey design, which is reliance on self-reporting. For example, the 'skills' sub-score was based upon the participants' self-perceived level of skill; we did not directly test a participant's knowledge or skills in EBP. It would be useful in future studies to correlate an actual "grade" from tests or quizzes of EBP knowledge with the self-reported survey data. Another inherent limitation is selection bias; it is possible that the 'attitudes' sub-scores were skewed toward higher values because participants were already in favor of an evidence-based practice paradigm prior to commencing the survey.

Although we had a relatively large number of survey responders $(\mathrm{n}=1,314)$, this number represents only a small proportion of the approximately 60,000 licensed chiropractors in the US. We made some minor modifications in the original EBASE questionnaire, chiefly to use the word "chiropractic" in certain questions. We do not believe these minor changes altered the intrinsic properties of the EBASE, however we did not formally conduct a psychometric evaluation of this modified version.

\section{Conclusion}

The results of this survey have provided new insights into the attitudes, skills and use of EBP among US chiropractors. The information gained from this survey will be most helpful in informing the design of future educational interventions for chiropractors to improve their level of EBP literacy and use of evidence in clinical practice. Overall, American chiropractors appear very similar to chiropractors in other countries, as well as other health professionals in terms of their favorable attitudes towards EBP, while expressing limitations and barriers related to EBP skills, research relevance, and lack of time. This suggests that the design of future EBP interventions for chiropractic should capitalize on the growing body of EBP implementation research evidence developing in other health disciplines. This will likely include broadening the approach beyond a sole focus on EBP education, and taking a multilevel approach that also targets professional, organizational and health policy domains.

\section{Additional file}

Additional file 1: EBASE Questionnaire and Scoring Rubric.

Abbreviations

ACA: American Chiropractic Association; CAM: Complementary and Alternative Medicine; DELIVER: Distance Education Online Intervention for 
Evidence-Based Practice Literacy; DC: Doctor of Chiropractic; EBP: Evidence-Based Practice; EBASE: Evidence-Based Practice Attitude and Utilization Survey; UPitt: University of Pittsburgh; NCCAM: National Center for Complementary and Alternative Medicine.

\section{Competing interests}

The authors declare that they have no competing interests.

\section{Authors' contributions}

MS was the principal investigator of the DELIVER study and was responsible for securing the funding and administration of the research grant. He was responsible for data collection, analysis, and a majority of the manuscript preparation. RE contributed to the conceptualization, design and funding acquisition of this work; she participated in data collection implementation and monitoring as well as decisions regarding data analysis and interpretation of results. She worked with the primary author to prepare the manuscript for publication and contributed content to the background and discussion sections. MH was responsible for assisting in designing the study, and interpretation of findings, as well as drafting and editing the manuscript. GC contributed to the initial concept and design of the study, was involved in meetings assessing progress, and critically reviewed the drafts of the manuscript, including data analyses. $\mathrm{CH}$ contributed to the initial concept and design of the study, interpretation of findings, as well as editing the manuscript. $M L$ was involved in the design and funding of the study, development of the outcome measure, drafting of the methods, and editing of the draft and final manuscript. CL contributed to the initial concept and design of the study, was involved in meetings assessing progress, and critically reviewed the drafts of the manuscript, including data analyses. CV worked with the primary author and co-authors to prepare the manuscript. She also participated in the implementation of Phase II of the DELIVER study. OW made significant contributions to the conception and design, acquisition and analysis of data; he was involved in drafting/revising the manuscript and gave final approval of the version to be published. LT performed the statistical analyses of the data and assisted with the interpretations of the results. She prepared the tables and worked with the primary author to write the methods, statistical analyses, and results sections of the manuscript. All authors read and approved the final manuscript.

\section{Acknowledgements}

This research was made possible by Grant Number R21AT007547 from the National Center for Complementary and Integrative Health $(\mathrm{NCClH}$; formerly NCCAM) at the National Institutes of Health (NIH). The views expressed in this article are solely those of the authors and do not necessarily represent the official views of the $\mathrm{NCCIH}, \mathrm{NCCAM}$ or $\mathrm{NIH}$.

The authors would like to acknowledge the hard work and assistance of our senior research associate Kris Gongaware and our research coordinator Christine McFarland. We would also like to acknowledge the important contributions of our database and information technology consultant Jack Doman.

\section{Author details}

${ }^{1}$ Department of Physical Therapy, School of Health and Rehabilitation Sciences, Clinical and Translational Science Institute, University of Pittsburgh, Pittsburgh, PA, USA. ${ }^{2}$ Center for Spirituality and Healing, Integrative Health and Wellbeing Research Program, University of Minnesota, Minneapolis, MN, USA. ${ }^{3}$ University of Western States, Portland, OR, USA. ${ }^{4}$ School of Nursing and Midwifery, University of South Australia, Adelaide, SA, Australia. ${ }^{5}$ Logan College of Chiropractic, Chesterfield, MO, USA. ${ }^{6}$ Palmer Center for Chiropractic Research, Palmer College of Chiropractic, Davenport, IA, USA. ${ }^{7}$ National University of Health Sciences, Lombard, IL, USA. ${ }^{8}$ The Commonwealth Medical College, Scranton, PA, USA. 'Department of Occupational Therapy, School of Health and Rehabilitation Sciences, University of Pittsburgh, Pittsburgh, PA, USA.

Received: 5 December 2014 Accepted: 7 April 2015 Published online: 04 May 2015

\section{References}

1. Sackett DL, Rosenberg WM, Gray JA, Haynes RB, Richardson WS. Evidence based medicine: what it is and what it isn't. BMJ. 1996;312:71-2.
2. Claridge JA, Fabian TC. History and development of evidence-based medicine. World J Surg. 2005;29:547-53.

3. Balakas K, Potter P, Pratt E, Rea G, Williams J. Evidence equals excellence: the application of an evidence-based practice model in an academic medical center. Nurs Clin North Am. 2009:44:1-10.

4. Glasziou P, Ogrinc G, Goodman S. Can evidence-based medicine and clinical quality improvement learn from each other? BMJ Qual Saf. 2011;20:13-7.

5. Ubbink DT, Guyatt GH, Vermeulen H. Framework of policy recommendations for implementation of evidence-based practice: a systematic scoping review. BMJ Open. 2013; doi:10.1136/bmjopen-2012-001881.

6. Cabana MD, Rand C, Powe N, Wu A, Wilson M, Abboud P, et al. Why don't physicians follow clinical practice guidelines? A framework for improvement. JAMA. 1999;282(15):1458-65.

7. Academic Consortium for Complementary \& Alternative Health Care, Competencies for Optimal Practice in Integrated Environments. 2011. http://accahc.org/images/stories/

accahc_competencies_optimal_february2012.pdf. Accessed 3 February 2015.

8. Evans R, Maiers M, Delagran L, Kreitzer MJ, Sierpina V. Evidence informed practice as the catalyst for culture change in CAM. Explore. 2012;8(1):68-72

9. Haas M, Leo M, Peterson D, Lefebvre R, Vavrek D. Evaluation of the effects of an evidence-based practice curriculum on knowledge, attitudes, and self-assessed skills and behaviors in chiropractic students. J Manipulative Physiol Ther. 2012;35(9):701-9.

10. Sullivan BM, Furner SE, Cramer GD. Development of a Student Mentored Research Program between a Complementary and Alternative Medicine University and a Traditional, Research Intensive University. Acad Med. 2014;89(9):1220-6.

11. Cramer GD, Guiltinan J, Maiers M, Laird S, Goertz C, Furner SE, et al. Benefits, Challenges And Culture Change Related To Collaborations Between Complementary And Alternative Medicine And Traditional Research-Intensive Institutions. Med Sci Educator. 2014. doi:10.1007/s40670-014-0077-3.

12. Shaw $L$, Descarreaux $M$, Bryans $R$, Duranleau M, Marcoux $H$, Potter $B$, et al. A systematic review of chiropractic management of adults with WhiplashAssociated Disorders: recommendations for advancing evidence-based practice and research. Work. 2010;35(3):369-94.

13. Bussieres A, Stuber K. The Clinical Practice Guideline Initiative: A joint collaboration designed to improve the quality of care delivered by doctors of chiropractic. J Can Chiropr Assoc. 2013;57(4):279-84.

14. Hawk C, Schneider M, Evans Jr MW, Redwood D. Consensus Process to Develop a Best-Practice Document on the Role of Chiropractic Care in Health Promotion, Disease Prevention, and Wellness. J Manipulative Physiol Ther. 2012;35(7):556-67.

15. Hawk C, Schneider M, Dougherty P, Gleberzon B, Killinger L. Best practices recommendations for chiropractic care for older adults: results of a consensus process. J Manipulative Physiol Ther. 2010;33(6):464-73.

16. Hawk C, Schneider M, Ferrance R, Hewitt E, Van Loon M, Tanis L. Best practices recommendations for chiropractic care for infants, children, and adolescents: results of a consensus process. J Manipulative Physiol Ther. 2009;32(8):639-47.

17. Institute of Medicine Committee on Quality of Health Care in America Crossing the quality chasm: a new health system for the 21 st century. Washington, DC: National Academies Press; 2001.

18. Schillinger D. An Introduction to Effectiveness, Dissemination and Implementation Research. P. Fleisher and E. Goldstein, eds. From the Series: UCSF Clinical and Translational Science Institute (CTSI) Resource Manuals and Guides to Community-Engaged Research, P. Fleisher, editor. Published by Clinical Translational Science Institute Community Engagement Program, University of California San Francisco; 2010.

19. Walker BF, Stomski N, Hebert J, French S. A survey of Australian chiropractors' attitudes and beliefs about evidence-based practice and their use of research literature and clinical practice guidelines. Chiropr Man Therap. 2013;21(1):44.

20. Suter E, Vanderheyden L, Trojan L, Verhoef M, Armitage G. How important is research-based practice to chiropractors and massage therapists? J Manipulative Physiol Ther. 2007;30(2):109-15.

21. Hall G. Attitudes of chiropractors to evidence-based practice and how this compares to other healthcare professionals: a qualitative study. Clin Chiropractic. 2011;14:106-11.

22. Roecker CB, Long C, Vining R, Lawrence D. Attitudes toward evidence-based clinical practice among doctors of chiropractic with diplomate-level training in orthopedics. Chiropr Man Therap. 2013;21(1):43. 
23. Putting evidence into practice: Dr. Michael Schneider talks about the DELIVER study. Dynamic Chiropractic. Feb 1, 2013. http://www.dynamicchiropractic.com/ mpacms/dc/article.php?id=56343. Accessed 13 Feb 2015

24. Your Opinion Counts. J Amer Chiropr Assoc. 2012;49(6):33. http://www.acatoday.org/content_css.cfm?CID=5060.

25. Leach MJ, Gillham D. Evaluation of the Evidence-Based practice Attitude and utilization SurvEy for complementary and alternative medicine practitioners. J Eval Clin Pract. 2008;14(5):792-8.

26. Leach MJ, Gillham D. Are complementary medicine practitioners implementing evidence based practice? Complement Ther Med. 2011;19(3):128-36.

27. Christensen MG, Kerkhoff D, Kollash M. Job Analysis of Chiropractic. Greeley, CO: National Board of Chiropractic Examiners; 2000

28. Christensen MG, Kollash M, Ward R, Webb K, Day M. zum Brunnen J. Job Analysis of Chiropractic. Greeley, CO: National Board of Chiropractic Examiners; 2005

29. Christensen MG, Kollash M, Hyland J. Job Analysis of Chiropractic. Greeley, CO: National Board of Chiropractic Examiners; 2010

30. Gaglio B, Phillips SM, Heurtin-Roberts S, Sanchez MA, Glasgow RE. How pragmatic is it? Lessons learned using PRECIS and RE-AIM for determining pragmatic characteristics of research. Implement Sci. 2014;9:96.

31. Slawson DC, Shaughnessy A. Teaching evidence-based medicine: Should we be teaching information management instead? Acad Med. 2005;80:685-9.

32. Murthy L, Shepperd S, Clarke MJ, Garner SE, Lavis JN, Perrier L, Roberts NW, Straus SE. Interventions to improve the use of systematic reviews in decision-making by health system managers, policy makers and clinicians. Cochrane Database Syst Rev. 2012;Issue 9. Art. No.: CD009401. doi:10.1002/14651858.CD009401.pub2.

33. Zwickey H, Schiffke $H$, Fleishman S, Haas M, Cruser D, LeFebvre R, et al. Teaching Evidence-Based Medicine at Complementary and Alternative Medicine Institutions: Strategies, Competencies, and Evaluation. J Altern Complement Med. 2014;20(12):925-31.

34. Long CR, Ackerman D, Hammerschlag R, Delagran L, Peterson D, Berlin M, et al. Faculty development initiatives to advance research literacy and evidence-based practice at CAM academic institutions. J Altern Complement Med. 2014:20(7):563-70.

35. Clar C, Tsertsvadze A, Court R, Hundt GL, Clarke A, Sutcliffe P. Clinical effectiveness of manual therapy for the management of musculoskeletal and non-musculoskeletal conditions; systematic review and update of UK evidence report. Chiropr Man Therap. 2014;28(22):1.

36. Bartholomew LK, Parcel GS, Kok G, Gottlieb NH. Planning Health Promotion Program: An Intervention Mapping Approach. San Francisco, California: Jossey-Bass; 2006.

37. French SD, Green SE, O'Connor DA, McKenzie JE, Francis JJ, Michie S, et al. Developing theory-informed behaviour change interventions to implement evidence into practice: a systematic approach using the Theoretical Domains Framework. Implement Sci. 2012;7:38

38. QUERI Implementation Guide Quality Enhancement Research Initiative. US Department of Veterans Affairs; 2014. http://www.queri.research.va.gov/ implementation/default.cfm Accessed 4 December 2014.

39. Kawchuk G, Newton G, Srbely J, Passmore S, Bussières A, Busse J, et al. Knowledge transfer within the Canadian Chiropractic Community. Part 2: Narrowing the evidence-practice gap. J Can Chiropr Assoc. 2014;58(3):206-14

\section{Submit your next manuscript to BioMed Central and take full advantage of:}

- Convenient online submission

- Thorough peer review

- No space constraints or color figure charges

- Immediate publication on acceptance

- Inclusion in PubMed, CAS, Scopus and Google Scholar

- Research which is freely available for redistribution 